\title{
Comparing Anxiety and Professional Efficiency Among Normal- and Over -Weight Medical Staff During the Covid-19 Outbreak: A Case-Control Study
}

\author{
Farhad Vahid ${ }^{1 *}$, Wena Rahmani ${ }^{2}$, Diana Rahmani ${ }^{2}$ and Sayed Hossein Davoodi ${ }^{3}$ \\ ${ }^{1}$ Department of Population Health, Luxembourg Institute of Health, Europe \\ ${ }^{2}$ Arak University of Medical Science, Iran \\ ${ }^{3}$ Department of Cellular and Molecular Nutrition, Shahid Beheshti University of Medical Sciences, Iran
}

Submission: October 10, 2021; Published: October 29, 2021

*Corresponding author: Farhad Vahid, Department of Population Health, Luxembourg Institute of Health, Europe

\section{Abstract}

Background: The professional efficiency of personnel and medical staff is among the most critical issues in the Covid-19 pandemic. Studies have shown that being obese/overweight is among the causes of anxiety and related to reduced professional efficiency. This study aimed to compare anxiety and professional efficiency among normal- and overweight/obese medical staff during the Covid-19 outbreak.

Methods: To conduct this study, 82 overweight/obese and 79 normal-weight healthcare employees at the Arak University of Medical Science, Arak, Iran, were participated. The Beck Anxiety Inventory (BAI) a valid, reliable, and self-report questionnaire applied to measure anxiety. Weight, height, and other demographic information were recorded. Body mass index (BMI) was calculated by dividing weight (kg) by height (m) squared.

Results: Results obtained from modeling BMI as a continuous variable concerning BAI showed a positive and significant association after adjustment for age and gender ( $\mathrm{OR}=2.61,95 \% \mathrm{CI}=1.32-5.16)$ and in the multivariate analysis ( $\mathrm{OR}=2.83,95 \% \mathrm{CI}=1.33-5.99)$. In addition, there was a significant association between $\mathrm{BAI}$ and medical staff professional efficiency (OR=0.599, $95 \% \mathrm{CI}=0.405-0.885)$. Also, a significant correlation was seen between BMI and BAI scores.

Conclusions: Our findings add to the growing evidence that BMI is an independent predictor of mental disorders and can reduce professional efficiency. As conclusion, training individuals on the harms of obesity and mental readiness to reduce mental disorders can effectively combat disasters.

Keywords: Beck anxiety inventory; Body mass index; Coronavirus; Overweight; Severe acute respiratory syndrome

Abbreviations: BMI: Body Mass Index; BAI: Beck Anxiety Inventory; SARS: Severe Acute Respiratory Syndrome; MERS: Middle East Respiratory Syndrome; WHO: World Health Organization; OR: Odds Ratio; CI: Confidence Intervals

\section{Introduction}

Anxiety is a diffuse, unpleasant, and vague feeling of fear, and its origin is unknown, which causes uncertainty, helplessness, and physiological arousal [1,2]. The recurrence of previously stressful situations or during which the person has been injured causes anxiety in people. All human beings suffer from anxiety in their lives, but chronic and severe anxiety is unusual and problematic [2]. In psychology, anxiety is an advanced stage of chronic stress. It becomes a mental health problem when, for example, it causes discomfort to the person or those around them or prevents a person from achieving their goals and when daily and regular activities are disrupted [2]. Anxiety can also affect professional performance and efficiency [3]. In general, environmental factors include sudden and unexpected changes, such as earthquakes, illness, and a loved one's death, which can contribute to anxiety [4]. In addition to knowing the causes of anxiety, it is essential to evaluate carefully and exam it. The Beck Anxiety Inventory (BAI) is a valid, reliable, and self-report questionnaire designed to measure the severity of anxiety in adults [5,6]. The questionnaire is a 21 -item scale in which the subject chooses one option that 


\section{Current Research in Diabetes \& Obesity Journal}

gives the intensity of anxiety [6]. Each test group describes one of the most common anxiety symptoms (mental, physical, and panic symptoms) [6]. Coronavirus disease (COVID-19) caused by severe acute respiratory syndrome coronavirus 2 (SARS-CoV-2) as a pandemic is an environmental factor that contributes to anxiety [7]. One of the most critical issues in this pandemic is the involvement of personnel and medical staff. According to reports, significant numbers of responding healthcare workers are infected with the virus worldwide [7]. Consequently, maintaining healthcare workers' efficiency to deal with the pandemic is exceptionally vital.

On the other hand, studies have shown that poor nutrition and being overweight or obese are among the causes of anxiety, and overweight people are more likely to be anxious [8-11]. The possible mechanisms of the association between overweight/ obesity and anxiety have not been well demonstrated, but it appears that hormonal and neurotransmitters changes can cause anxiety in these individuals [12]. Obesity and overweight are common problems in societies and impose substantial healthcare costs [13]. So, in the USA, 41 percent of people have some degree of obesity $[14,15]$. According to a study, overweight or obesity combined and obesity statistics in low- and middle-income countries were $31.5 \%$ (8.8-85.3\%) and $10.2 \%$ (1.9-48.8\%), respectively [16]. In addition to non-communicable diseases such as diabetes, cardiovascular disease, high blood pressure, and various cancers, obesity is also associated with behavioral and psychological disorders [17]. Therefore, it seems to be a difference between normal-weight people and overweight/obese ones in dealing with disasters, such as those that occur in pandemics. Since medical staff/healthcare workers are high-risk groups in the spread of infectious diseases [7] and due to high awareness, changing working hours, insufficient rest, and other factors are more at risk for mental disorders such as anxiety. Due to the prevalence of Covid-19 and the unknown factors of this virus pathology, and the insufficient and inaccurate information about the prevention, treatment, and control of this virus, it seems that the incidence of mental disorders, including anxiety, may increase. This study aimed to investigate anxiety and professional efficiency in normal- and over-weight-personnel and medical staff.

\section{Methods}

Full protocol and method of the study published elsewhere [18]. Data were collected from 78 normal-weight medical staff and personnel (as the control group) and 82 overweight/obese (BMI>25) (as case group) at Arak University of Medical Science (AUMS), Arak, Iran. The relevant committee also approved the final version of the article. Conscious consent was required, so only those who were fully willing to participate entered the study. The BAI questionnaire was available online through the university portable to personnel and medical staff. The BAI can be used online on smartphones, and computer systems were given to all personnel and medical staff of AUMS who were eligible to enter the study and wish to cooperate. Sampling was done through the university portal and in the form of public information. The link to the questionnaires was provided to all staff and personnel. Weight, height, and other demographic data were recorded self-reportedly. The School of Health of the Arak University of Medical Sciences and Research Core entitled "Covid-19" at Arak University of Medical Sciences Research and Ethics Committee were approved the study protocol. The code of ethics number I.R.ARAKMU.REC.1398.330 was assigned to this study. Written informed consent was obtained from all study participants

\section{Inclusion and exclusion criteria}

a) Be one of the personnel and medical staff of AUMS.

b) Having at least one year of work experience in AUMS.

c) Be present in AUMS at the pandemic.

d) Has not retired during the pandemic.

e) She/he or a family member did not have the disease or did not show any symptoms.

f) Willingness to cooperate

g) Does not be a volunteer staff.

\section{Statistical analysis}

Descriptive analyses were carried out using a t-test for the continuous variables and a chi-square test for the categorical variables. The BMI (as a dichotomous variable) was examined across the following characteristics: age, sex, education, smoking, income level, job category, tenure, and marital status. Analyses focusing on the association of BMI scores and BAI were carried out using BAI as a continuous variable. For studies focusing on $\mathrm{BAI}$ as an outcome, the BAI was analyzed as a continuous variable. Odds Ratio (OR) and 95\% confidence intervals (CI) for the BMI were estimated using linear regression and OR and 95\% CI for $\mathrm{BAI}$ as an outcome was assessed using logistic regression models, adjusting for age and gender, and then fitting a model with additional adjustment for the job category, education, smoking, marriage status, income level, and having direct contact with Covid-19 patients. The partial correlation was used to estimate the coefficients between BMI and BAI scores in the subjects. Statistical tests were performed using SPSS 25 ; all $p$ values were based on two-sided tests.

\section{Results}

Table 1 shows the distribution of 78 normal-weight participants (BMI $\leq 24.99$ ) and 82 overweight/obese (BMI>25) according to selected variables. A partial correlation between BMI and BAI scores has been shown in Table 2. According to Table 2, a significant correlation was seen between BMI and BAI scores after controlling for (gender), (age and gender), (gender and marital status), and (age, gender, marital status); however, a reverse correlation was seen between BMI and compliance none of the correlations were significant. In addition, there was an inverse correlation between BMI and performance. There was an insignificant correlation between BMI and performance after controlling for age, marital status, and gender (correlation= -0.154; P-value=0.055). According to continuous and cut points 


\section{Current Research in Diabetes \& Obesity Journal}

of BMI, OR, and 95\% CI for the BAI scores are shown in Table 3. The results obtained from modeling BMI as a constant variable concerning BAI showed a positive association in the multivariate analysis ( $\mathrm{OR}=2.83,95 \% \mathrm{CI}=1.33-5.99)$ after adjustment for age and gender $(\mathrm{OR}=2.61,95 \% \mathrm{CI}=1.32-5.16)$. When the analysis was carried out with BMI as a dichotomous variable and adjusted for age and gender, subjects with normal weight were at 1.12 times higher odds of having higher BAI scores than overweight/ obese subjects ( $\mathrm{OR}=1.12,95 \% \mathrm{CI}=1.01-1.25)$. After multivariable adjustment, subjects with normal weight subjects were at 1.13 times higher odds of having higher BAI scores than overweight/ obese subjects $(\mathrm{OR}=1.13,95 \% \mathrm{CI}=1.01-1.28)$. Table 4 shows ORs and $95 \%$ CIs for the association between BAI scores and staff performance and compliance. According to Table 4, the results obtained from modeling performance as a continuous variable concerning BAI showed an insignificant association after adjustment for age and gender (OR=0.914, 95\% CI=0.7511.111) and a significant association in the multivariate analysis (OR=0.599, 95\% CI=0.405-0.885). When we entered compliance as a quantitative variable in models, a significant association was observed between the BAI and the compliance. After adjusting for age and gender, OR and 95\% CI for BAI and compliance were $0.078,95 \%$ CI $0.020-0.314$, showing that with increasing BAI scores, compliance with medical principles decreases. In addition, these results were significant after multivariate adjustment (OR=0.018, 95\% CI=0.002-0.154).

Table 1: Distribution of 78 normal weight $(\mathrm{BMI} \leq 24.99)$ and 82 overweight/obese $(\mathrm{BMI}>25)$ to selected variables a, b

\begin{tabular}{|c|c|c|c|}
\hline \multirow[b]{2}{*}{ Characteristics } & \multicolumn{2}{|c|}{ Mean \pm SD or $N(\%)$} & \multirow{2}{*}{ P-value } \\
\hline & Normal Weight $(n=78)$ & Overweight/Obese $(n=82)$ & \\
\hline Beck Anxiety Inventory scores d & 72.48 & 86.15 & $<0.01$ \\
\hline Age (year) & & & 0.74 \\
\hline $20-39$ & $45(57.69)$ & $50(60.97)$ & \\
\hline $40-59$ & $33(42.30)$ & $32(39.02)$ & \\
\hline Job & & & 0.3 \\
\hline University Teaching Stuff & $10(12.82)$ & $12(14.63)$ & \\
\hline Healthcare Professional & $50(64.10)$ & $51(62.19)$ & \\
\hline Lab Professionals & $18(23.07)$ & 19 (23.17) & \\
\hline Tenure (year) & $10.15 \pm 6.84$ & $9.95 \pm 5.86$ & 0.84 \\
\hline Marital status & & & 0.29 \\
\hline Married & $42(53.84)$ & $54(65.85)$ & \\
\hline Single/divorced/widow & $36(46.15)$ & $28(34.14)$ & \\
\hline Sex & & & 0.05 \\
\hline Females & $49(62.82)$ & $39(48.75)$ & \\
\hline Education & & & 0.1 \\
\hline Lower than a bachelor's degree & $40(51.28)$ & $53(64.64)$ & \\
\hline Higher than a bachelor's degree & $38(48.71)$ & $29(35.35)$ & \\
\hline Smoking status & & & 0.06 \\
\hline Never smoked & $53(67.94)$ & $41(50.00)$ & \\
\hline Smoking & $15(19.23)$ & $26(31.70)$ & \\
\hline Used to smoke & $10(12.82)$ & $15(18.29)$ & \\
\hline Income (Rials) & & & $<0.01$ \\
\hline Up to 50 million Rials & $26(33.33)$ & $40(48.78)$ & \\
\hline Above 50 million Rials & $52(66.66)$ & $42(51.21)$ & \\
\hline Taking stress and anxiety control medicines & & & 0.63 \\
\hline No & $67(85.89)$ & $73(89.02)$ & \\
\hline Direct contact with patients with Covid-19 & & & 0.51 \\
\hline No & $39(50.00)$ & $42(51.21)$ & \\
\hline
\end{tabular}

a Comparison of mean of normal - overweight groups in case of normal distribution of variables by t-test and in case of abnormal distribution of variables by Mann-Whitney test.

b Chi-square was used for categorical variables.

d Mean Rank 


\section{Current Research in Diabetes \& Obesity Journal}

Table 2: Partial correlation between Body Mass Index (BMI) a and Beck Anxiety Inventory (BAI) b scores, performance, and compliance.

\begin{tabular}{|c|c|c|c|c|c|c|}
\hline Adjusted Factor & \multicolumn{2}{|c|}{ BMI \& BAI Scores } & \multicolumn{2}{c|}{ BMI \& Performance } & \multicolumn{2}{c|}{ BMI \& Compliance } \\
\hline & Correlation & $\begin{array}{c}\text { Significance } \\
\text { (2-Tailed) }\end{array}$ & Correlation & $\begin{array}{c}\text { Significance } \\
\text { (2-Tailed) }\end{array}$ & Correlation & $\begin{array}{c}\text { Significance } \\
\text { (2-Tailed) }\end{array}$ \\
\hline Age & 0.144 & 0.07 & -0.144 & 0.71 & -0.11 & 0.16 \\
\hline Age and Education & 0.124 & 0.12 & -0.15 & 0.05 & -0.039 & 0.62 \\
\hline Age and Marital status & 0.141 & 0.07 & -0.154 & 0.05 & -0.108 & 0.75 \\
\hline Age and Gender & 0.16 & 0.04 & -0.144 & 0.07 & -0.094 & 0.24 \\
\hline Age and Income Levels & 0.133 & 0.09 & -0.123 & 0.12 & -0.086 & 0.28 \\
\hline Gender & 0.16 & 0.04 & -0.144 & 0.07 & -0.094 & 0.23 \\
\hline Gender and Education & 0.135 & 0.091 & -0.151 & 0.05 & -0.021 & 0.79 \\
\hline Gender and Marital status & 0.163 & 0.04 & -0.152 & 0.05 & -0.092 & 0.24 \\
\hline Gender and Income Levels & 0.144 & 0.07 & -0.123 & 0.12 & -0.077 & 0.33 \\
\hline Age, Gender, Education & 0.14 & 0.08 & -0.123 & 0.12 & -0.076 & 0.34 \\
\hline Age, Gender, Marital status & 0.156 & 0.05 & -0.154 & 0.05 & -0.093 & 0.24 \\
\hline Age, Gender, Income Levels & 0.149 & 0.06 & -0.123 & 0.12 & -0.069 & 0.39 \\
\hline Age, Gender, Education, Marital Status, & 0.136 & 0.09 & -0.152 & 0.05 & -0.03 & 0.71 \\
\hline Income & & & & 0.03 \\
\hline
\end{tabular}

a As a categorical variable [78 normal weight (BMI $\leq 24.99)$ and 82 overweight/obese (BMI>25)]

b As a continuous variable.

Table 3: Odds ratios and confidence intervals for the association between the Beck Anxiety Inventory (BAI) scores and Body Mass Index (BMI).

\begin{tabular}{|c|c|c|c|c|}
\hline Models & BMI as a Continuous Variable OR (95\% CI) & P-value & BMI as a Categorical Variable a OR (95\% CI) & P-value \\
\hline Model A & $2.61(1.32-5.16)$ & $<0.01$ & $1.12(1.01-1.25)$ & 0.02 \\
\hline Model B & $2.83(1.33-5.99)$ & $<0.01$ & $1.13(1.01-1.28)$ & 0.03 \\
\hline
\end{tabular}

Model A: adjusted for age and gender

Model B: adjusted for age, gender, job category, education, smoking, marriage status, income level, and having direct contact with Covid-19 patients

a78 normal weight (BMI $\leq 24.99)$ and 82 overweight/obese (BMI>25).

Table 4: Odds ratios and confidence intervals for the association between the Beck Anxiety Inventory (BAl) scores and staff performance and compliance $(n=160)$

\begin{tabular}{|c|c|c|c|c|}
\hline Models & Performance & P-value & Compliance & P-value \\
\hline & OR $(95 \% \mathrm{CI})$ & & OR $(95 \% \mathrm{CI})$ & $<0.01$ \\
\hline Model A & $0.914(0.751-1.111)$ & 0.36 & $0.078(0.020-0.314)$ & $<0.01$ \\
\hline Model B & $0.599(0.405-0.885)$ & $<0.01$ & $0.018(0.002-0.154)$ & $<$
\end{tabular}

Model A: adjusted for age and gender

Model B: adjusted for age, gender, job category, education, smoking, marriage status, income level, and having direct contact with Covid-19 patients

\section{Discussion}

Our study results showed that overweight/obese personnel/ staff had higher anxiety scores than normal-weight ones. Our study showed that increased anxiety was more common in overweight/obese personnel/staff. Some studies have shown that obese people are more likely to experience stress and anxiety [19]. A study analyzed 177047 participants' data [19], a significant difference in the prevalence of current depression, lifetime diagnosed depression, and anxiety among people with different BMI levels, independent of their disease status or other psychosocial or lifestyle factors [19]. Various factors can cause anxiety in overweight/obese people, such as hormonal changes (imbalance), social factors such as social stigma, or others, as well as low physical activity $[20,21]$. Although due to the heterogeneity of the causes of obesity, it cannot be considered one or more factors [21]. Some studies have shown that anxiety or stress itself can cause obesity [21]. It is difficult to determine the cause-and- 
effect relationship. Whether obesity has caused mental disorders or mental disorders has caused obesity [21]. Various factors cause this vicious cycle, in which obesity increases. Markowitz et al. combined the causes and mechanisms of biochemistry, social, cultural, and others to show the complicated relationship between BMI and depression [22]. On the other hand, Scott et al. concluded a modest and/or no significant relationship between obesity and mental disorders in women [23]. However, according to their report, since the self-report of BMI limited the study, it could be a reason that they could not clarify the direction or nature of the relationship [23]. Although our study was based on a self-report of BMI, we report promising results contrary to Scott et al. [24] One of the most important factors influencing the fight against diseases is the performance and adherence of personnel to protocols. Studies have shown that staff adherence to protocols can be crucial to disease control [24,25]. Clawson et al. [26] showed that compliance with protocols could increase organizational efficiency. In addition, there is a theory that performance is affected by anxiety [27]. Our study showed an inverse relationship between BMI and adherence to health protocols (compliance). However, the relationship was not significant, but this inverse relationship in the study with a relatively low sample size could be very encouraging. However, in some studies, this relationship was significant [28]. Nishitani et al. [28] showed that eating behavior could be affected by psychological job stress responses such as stress/anxiety and depression. On the other hand, we also observed a significant inverse relationship between BMI and performance. Some studies have confirmed this finding $[29,30]$. Han et al. found an inverse relationship between obesity and jobrelated physical exertion [29]. Our study results showed that an increase in BMI score increases the odds of the BAI score. These results were examined in different models, and in all of those models, the odds of growing anxiety scores increase with increasing BMI. On the other hand, there was an inverse relationship between anxiety and staff performance and compliance. Anxiety increases the odds of not adhering to protocols and reducing staff performance. After adjusting additional confounders, the odds of non-compliance and decreasing staff performance associated with high anxiety scores were observed. In a study by Kim et al., researchers found that anxiety disturbed daily functioning and reduced people's performance [31]. Other studies have suggested reducing performance concerning anxiety [32-34]. In addition, some studies showed that people with anxiety are more likely to disobey orders and do not adhere to protocols [34-37]. Therefore, it can be concluded that personnel in emergencies and under much pressure are more prone to mental disorders such as stress, anxiety, and depression. According to studies, overweight or obese people are more likely to have mental disorders. Their performance and adherence to protocols may be affected compared to people with normal weight. On the other hand, mental preparedness to deal with crises can reduce these effects. Therefore, having educational programs to reduce mental disorders and periodic reminders and teaching the harms of obesity can be a successful program to increase organizational efficiency. This strategy creates a win-win situation in which people will be healthier due to their weight in the normal range and reducing mental disorders.

\section{Study strengths}

This study is the first to examine the mental health of personnel and medical staff dealing with Covid-19 and compare overweight/ obese and normal people. Another strength of this study includes using a valid and reliable questionnaire, which assures us that the results are accurate and strong enough. Furthermore, this study is timely, as the data was collected in March 2020 and coincided with the peak of Covid-19, which allowed achieving the best estimates of the impact of independent variables. This study has a relatively acceptable sample size, as about one-fifth of involved personnel and medical staff participated.

\section{Study limitations}

Self-reporting of weight and height and the possible effect of recall bias is a limitation of this study. Besides, the study included a limited number of variables. Therefore, it is recommended that studies be conducted with different designs and considering a more comprehensive range of confounder variables.

\section{Conclusion}

Our findings added to the growing evidence that BMI is an independent predictor of mental disorders. On the other hand, obesity is associated with the nervous system's functioning, and obese people are more likely to get involved in mental disorders. In addition, with the outbreak of disasters such as the Covid-19, medical staff and personnel health systems are expected to perform at their productivity peak. Still, anxiety and stress reduce their efficiency and effectiveness, which is more common in obese/overweight people. As a result, training individuals to deal with obesity and keep them mentally ready to reduce mental disorders can effectively combat disasters.

\section{Declarations}

a) Ethics approval consent to participate: The School of Health of the Arak University of Medical Sciences and Research Core entitled "Covid-19" at Arak University of Medical Sciences Research and Ethics Committee were approved the study protocol. The code of ethics number I.R.ARAKMU.REC.1398.330 was assigned to this study. Written informed consent was obtained from all study participants.

b) Consent to publication: Not applicable.

c) Availability of data and materials: We do not wish to share our data because of our university/institute policies. 


\section{Current Research in Diabetes \& Obesity Journal}

d) Competing interests: The authors declare that they have no competing interests.

e) Funding: Not applicable.

f) Authors' contributions: Study concept and design: FV; acquisition of data: FV, DR; analysis and interpretation of data: WR, DR drafting of the manuscript: SHD, FV; critical revision of the manuscript: FV; statistical analysis: FV; obtained funding: SHD; administrative, technical, or material support.

Acknowledgments: We would like to thank Dr. Diyako Rahmani for the technical editing of the article.

\section{References}

1. McReynolds P (1990) The Concept of Anxiety. Background and Current Issues. Anxiety and the heart 1.

2. Beck AT, Emery G, Greenberg RL (2005) Anxiety disorders and phobias: A cognitive perspective. Basic Books.

3. McCarthy JM, Trougakos JP, Cheng BH (2016) Are anxious workers less productive workers? It depends on the quality of social exchange. J Appl Psychol 101(2): 279-291.

4. Barlow DH (1991) The nature of anxiety: Anxiety, depression, and emotional disorders pp. 1-28.

5. Fydrich T, Dowdall D, Chambless DL (1992) Reliability and validity of the Beck Anxiety Inventory. Journal of anxiety disorders 6(1): 55-61.

6. Steer RA, Beck AT (1997) Beck Anxiety Inventory.

7. The L: COVID-19 (2020) Protecting health-care workers. Lancet (London, England) 395: 922-922.

8. Ganley RM (1989) Emotion and eating in obesity: A review of the literature. International Journal of eating disorders 8(3): 343-361.

9. Eyres SL, Turner AI, Nowson CA, Torres SJ (2014) Does diet-induced weight change effect anxiety in overweight and obese adults? Nutrition 30(1): 10-15.

10. Brumpton B, Langhammer A, Romundstad P, Chen Y, Mai XM (2013) The associations of anxiety and depression symptoms with weight change and incident obesity: The HUNT Study. International journal of obesity 37(9): 1268-1274.

11. Vahid F, Rahmani D (2021) Can an anti-inflammatory diet be effective in preventing or treating viral respiratory diseases? A systematic narrative review. Clinical Nutrition ESPEN 43: 9-15.

12. Lykouras L, Michopoulos J (2011) Anxiety disorders and obesity. Psychiatriki 22(4): 307-313.

13. Dobbs R, Manyika J (2015) The obesity crisis. The Cairo Review of Global Affairs 5 .

14. Campos P, Saguy A, Ernsberger P, Oliver E, Gaesser G (2005) The epidemiology of overweight and obesity: public health crisis or moral panic? International Journal of Epidemiology 35(1): 55-60.

15. Nair KP (2020) Overweight and Obesity: The Bane of Modern Times. In Food and Human Responses. Springer pp. 173-203.

16. Reyes MU, Mesenburg MA, Victora CG (2020) Socioeconomic inequalities in the prevalence of underweight, overweight, and obesity among women aged 20-49 in low- and middle-income countries. International Journal of Obesity 44(3): 609-616.
17. Sharafi SE, Garmaroudi G, Ghafouri M, Bafghi SA, Ghafouri M, et al. (2020) Prevalence of anxiety and depression in patients with overweight and obesity. Obesity Medicine 17: 100169.

18. Rahmani D, Zeng C, Moazami GA, Vahid F (2021) Organizational compliance during the COVID-19: Investigating the effect of anxiety, productivity, and induvial risk factors among the Iranian healthcare employees. Frontiers in Communication 6: 7.

19. Zhao G, Ford ES, Dhingra S, Li C, Strine TW, et al. (2009) Depression and anxiety among US adults: associations with body mass index. International Journal of Obesity 33(2): 257-266.

20. Avila C, Holloway AC, Hahn MK, Morrison KM, Restivo M, et al. (2015) An overview of links between obesity and mental health. Current obesity reports 4(3): 303-310.

21. Talen MR, Mann MM (2009) Obesity and mental health. Primary Care: Clinics in Office Practice 36(2): 287-305.

22. Markowitz S, Friedman MA, Arent SM (2008) Understanding the relation between obesity and depression: causal mechanisms and implications for treatment. Clinical Psychology: Science and Practice 15(1): 1-20.

23. Scott KM, Bruffaerts R, Simon GE, Alonso J, Angermeyer M, et al. (2008) Obesity and mental disorders in the general population: results from the world mental health surveys. International Journal of Obesity 32(1): 192-200.

24. Pittet D (2001) Improving adherence to hand hygiene practice: a multidisciplinary approach. Emerging infectious diseases 7(2): 234240.

25. Pathmanathan I, O Connor KA, Adams ML, Rao CY, Kilmarx PH, et al. (2014) Rapid assessment of Ebola infection prevention and control needs - six districts, Sierra Leone, October 2014. MMWR Morbidity and mortality weekly report 63: 1172 .

26. Clawson JJ, Cady GA, Martin RL, Sinclair R (1998) Effect of a comprehensive quality management process on compliance with protocol in an emergency medical dispatch center. Annals of emergency medicine 32: 578-584.

27. Eysenck MW, Calvo MG (1992) Anxiety and performance: The processing efficiency theory. Cognition \& emotion 6(6): 409-434.

28. Nishitani N, Sakakibara H (2007) Relationship of BMI increase to eating behavior and job stress in a 2-year cohort study of non-obese male Japanese workers. Obesity Research \& Clinical Practice 1(3): 179185.

29. Han K, Trinkoff AM, Storr CL, Geiger-Brown J (2011) Job stress and work schedules in relation to nurse obesity. JONA 41(11): 488-495.

30. Jans MP, van den Heuvel SG, Hildebrandt VH, Bongers PM (2007) Overweight and obesity as predictors of absenteeism in the working population of the Netherlands. J Occup Environ Med 49(9): 975-980.

31. Kim MJ, Loucks RA, Palmer AL, Brown AC, Solomon KM (2011) The structural and functional connectivity of the amygdala: from normal emotion to pathological anxiety. Behavioural brain research 223: 403410.

32. Klinger E (1984) A consciousness-sampling analysis of test anxiety and performance. Journal of personality and Social Psychology 47(6): 1376.

33. Righi S, Mecacci L, Viggiano MP (2009) Anxiety, cognitive selfevaluation and performance: ERP correlates. Journal of Anxiety Disorders 23(8): 1132-1138. 
34. Akinsola EF, Nwajei AD (2013) Test anxiety, depression and academic performance: assessment and management using relaxation and cognitive restructuring techniques. Psychology 4: 18.

35. Zagożdżon P, Wrotkowska M (2017) Religious beliefs and their relevance for treatment adherence in mental illness: A review. Religions 8: 150.
36. Leib EJ (2007) The Perpetual Anxiety of Living Constitutionalism. Const Comment, 24: 353.

37. McNally RJ (1996) Cognitive bias in the anxiety disorders. In Nebraska symposium on motivation. University of Nebraska Press, pp. 211-250.

Your next submission with Juniper Publishers
will reach you the below assets
- Quality Editorial service
- Swift Peer Review
- Reprints availability
- E-prints Service
- Manuscript Podcast for convenient understanding
- Global attainment for your research
- Manuscript accessibility in different formats
( Pdf, E-pub, Full Text, Audio)
- Unceasing customer service
Track the below URL for one-step submission
https://juniperpublishers.com/online-submission.php

